\title{
INFORMATION TECHNOLOGIES IN THE FINANCING OF POLITICAL PARTIES (CASE STUDY OF THE REPUBLIC OF MOLDOVA)
}

\author{
Assistant Professor, PhD, Rodica Svetlicinâi, \\ Lecturer, PhD, Mariana Iațco, \\ Assistant Professor, PhD, Tatiana Turco \\ Republic of Moldova, Chisinau, Moldova State University \\ Faculty of International Relations, Political and Administrative Sciences, \\ Department of Political and Administrative Sciences
}

DOI: https://doi.org/10.31435/rsglobal_wos/31012019/6321

\section{ARTICLE INFO}

Received: 02 November 2018

Accepted: 10 January 2019

Published: 31 January 2019

\section{KEYWORDS}

Financing Political Parties; Electronic Reporting System; Transperancy of Financing Political Parties;

Donations and Subventions to Political Parties.

\begin{abstract}
The issue of reporting on the financial activity of political parties is crucial for any democratic society. At the same time, the presentation of financial reports by political parties is a mandatory element in ensuring greater transparency of their activity as a whole. Transparency of party financing activities is necessary to protect voters' rights to obtain the necessary information on financial support to political parties as well as the costs associated with running the electoral campaign, etc., which ensures a more trained and informed voter for the exercise of his / her rights in a democratic system. One way to increase the transparency of political parties' funding is the system of online reporting of political party incomes and expenditures. For the Republic of Moldova this is an a priori, given that our society has set its course towards European standards and values, and the political arena is characterized by the diversity of political actors segmented according to the ideals claimed in their platform and status.
\end{abstract}

Citation: Rodica Svetlicinâi, Mariana Iațco, Tatiana Turco. (2019) Information Technologies in the Financing of Political Parties (Case Study of the Republic of Moldova). International Academy Journal Web of Scholar. 1(31), Vol.2. doi: 10.31435/rsglobal_wos/31012019/6321

Copyright: (C) 2019 Rodica Svetlicinâi, Mariana Iatco, Tatiana Turco. This is an open-access article distributed under the terms of the Creative Commons Attribution License (CC BY). The use, distribution or reproduction in other forums is permitted, provided the original author(s) or licensor are credited and that the original publication in this journal is cited, in accordance with accepted academic practice. No use, distribution or reproduction is permitted which does not comply with these terms.

Introduction. Political financing is a vital issue for democracy, governance and development. Regardless of how the state holds elections, how active civil society is, political parties are competitive and local authorities are responsible, the role of money in politics undoubtedly affects the quality of democracy and governance. Only a high degree of transparency will allow you to fully understand the scope and nature of this effect [3:5].

An important aspect of the work of political parties is the reporting on their funding. Political actors, civil society, media are interested in having access to such information. To this end, the research aims at identifying the needs and opportunities of implementing an electronic reporting system that will ensure the quality of the process of supervising and controlling the work of political parties by research and evaluation of the current process of financial reporting of political parties. In order to achieve the proposed goal, the following objectives were set: determining the main features and functionalities of the electronic reporting system; to identify the degree of necessity of such a platform and the level of training, but also the expectations of the beneficiaries regarding the 
introduction of the electronic financial reporting system of the political parties in the Republic of Moldova (Central Electoral Commission and Political Parties) and of the users of this system. The novelty of the research lies in the fact that the theme of such a study in the Republic of Moldova was not a subject of scientific analysis, but rather a practical and scientific applicative approach.

The study was initiated within the project "Supporting the Central Electoral Commission in Developing an Electronic Reporting System on the Financing of Political Parties", implemented by the Electoral Training Center (CICDE) and IDEA International, in order to analyze and evaluate the perception of the groups target on the degree of necessity and content of an electronic financial reporting system for political party activity.

Methodological design of the study. In order to achieve the aim and objectives proposed, the principle of systemic analysis, the interdisciplinary approach, the combination of sociological and political methods were used. Primary data was obtained on the basis of empirical sociological research. By combining the two types of data, both qualitative and quantitative, the content of the study wishes to outline the views of target groups on the content of an electronic financial reporting system for political parties and the level of readiness for switching to such a system.

Three types of questionnaires were conducted, one addressed to the representatives of the Central Electoral Commission (CEC); the second - the political parties and the third representatives of the civil society. In this respect, in total, they have been achieved 30 personalized interviews with representatives of the CEC, political parties and civil society, from 15 December 2017 to 15 January 2018. The structure of the questionnaires for all target groups was structured in two compartments: general questions common to all respondents, and specific questions formulated according to the group's characteristics aim.

At the same time 2 focus groups (FG) were held with the members of the Central Electoral Commission and with the MA students of the Faculty of International Relations, Political and Administrative Sciences, State University of Moldova.

Social-demographic characteristics of the participants in the in-depth interviews. According to the age criterion, the participants in the in-depth interviews were divided into the following groups: up to 30 years $-14 \%$; 30-40 years - 34\%; $41-50$ years - $24 \%$; $51-60$ years $-21 \%$ and over 60 years $7 \%$. By gender, $44 \%$ of men and $56 \%$ of women were interviewed. Among respondents, $70 \%$ have higher education; $20 \%$ - master studies and $10 \%$ - scientific degree.

Research results. Currently, the reporting process on the financial activity of political parties involves an affinity between two subjects: the Central Electoral Commission and political parties. In addition to other tasks assigned to the CEC, it also exercises the function of overseeing and controlling the financing of the work of political parties, while the latter have the obligation to comply with the legal norms governing their work. An important indicator of the effectiveness of this process is the degree of transparency. The study addressed both aspects of this process, namely the level of supervision of financial management, as well as financial reporting.

The analysis of the data on the culture of supervision of the financial management of the activity of the political parties, as well as the degree of its transparency, denotes a mediocre situation. All respondents mentioned the absence of high transparent surveillance, while nobody specified that it did not exist at all.

Most of those interviewed by the CEC - 67\%, believes that in the Republic of Moldova there is an average transparent supervision culture of the financial management of the political parties' activity and only $1 / 3$ support that this surveillance culture is weak.

This situation can be explained by the fact that the very culture of supervising the financial management of the political parties is in the process of training and substantiation (some amendments to the legislative framework have been made since 2016, the Regulation on Financing the Activity of Political Parties) [1;2].

On the other hand, almost all political parties (95\%) noted that their organization has a culture of compliance with financial reporting requirements, for which a person in charge of treasurer's treasury finances is responsible for keeping track of funding sources and presenting financial reports to the CEC.

Only $5 \%$ of those interviewed indicated that the party does not comply with the financial reporting requirements, motivating the absence of a person specifically designated for it, and the treasurer's duties are often exercised by the president of the political party himself (it is specific to the non-systemic parties, the small, with an electorate and few supporters).

In the opinion of the CEC's respondents, the causes of a medium and weak transparent surveillance would be: deficiencies in the full execution of the control and supervision functions by the CEC (legal component "personal data", which is regulated by the Personal Data Protection Act); lack of effective leakage / verification tools; lack of qualified staff; superficial or very limited 
communication between CEC and political parties; parties are not interested in presenting data on the volume of donations.

An important aspect of the reporting process is the veracity of the information submitted to the CEC. As a result of the questionnaire, both CEC employees and representatives of civil society unanimously replied that, at this stage, financial reporting DO NOT reflect the reality of financing the work of political parties.

The same position was expressed by the focus groups surveyed, most of them (87\%) have responded negatively to the veracity of reported information:

„,... Of course, it does not fully reflect, nor has it in the society we live in. Things can not even be shown completely". (FG, female, 23 years old, Ialoveni).

But $13 \%$ believes the data is only ,partial” veridical (this explanation lies in the truthfulness of the reporting of subsidies from the state budget).

The causes that conditioned the negative responses of the CEC respondents were largely focused on the insufficiency of the supervision and control levers of the financial activity of the parties, but also on the superficial / non-qualitative character of exercising control over it.

On the other hand, civil society mentioned the inapplicability of the law, especially the imperfect regulatory framework on party financing. Also, reporting is affected by the lack of transparency regarding donations, which often make money in pre-electoral and electoral periods. Among other causes were the informal economic system, the existence of oligarchic groups, the phenomenon of corruption, bank fraud, the applicability of double standards to opposition parties.

Therefore, when identifying the causes, the CEC and civil society respondents had the same recommendations regarding the improvement of the financial reporting situation of political parties: establishing tougher sanctions for delayed / erroneous financial reporting, especially in electoral campaigns (up to non-admission to elective participation); determining more clearly the provenance and source of party financial means; party financial information should be public and accessible.

Within the focus groups surveyed, there are the same recommendations and opinions on the tightening of sanctions on political parties.

In order to increase the quality of reporting, but also the process itself, the CEC proposes an extensive information campaign on the essence and mode of financial reporting, and this process must necessarily include the automation component of data processing. For civil society, it is important for this process to be transparent, characterized by the publicity, veracity and accessibility of data.

In this context, survey data reflects the imperative of implementing a system of electronic reporting of political party income and expenditures (100\% of the CEC's respondents answered yes), while only $75 \%$ of respondents in the civil society believe that this electronic system is absolutely necessary to ensure financial reporting $13 \%$ - quite necessary.

For the focus groups surveyed this process is one ,positive, welcome and innovative” (100\% of the respondents), considering it the first step to ensure the transparency of the process of financing political parties.

„...It is a huge step towards the democratization of society and the transparency of the national political scene". (FG, male, 26 years, Chisinau).

„,...it would be better for us to find information faster and download and process data compared to other reports, for example, developed by civil society". (FG, female, 38 years old, Chisinau).

A different opinion had respondents from political parties, of which $5 \%$ considers it unnecessary to implement the electronic reporting system. For $45 \%$ this system is quite necessary, and $39 \%$ considers it necessary, which presumes that the current reporting system is satisfying as it is, and an electronic reporting innovation is welcome but would not radically change the working status of this surveillance segment.

Considering that the introduction of a digital report on the funding of political parties is absolutely necessary not only for the CEC, civil society representatives also reiterated its usefulness, highlighting the informational contribution that this electronic system can generate. Firstly, for the associative sector it is important: be informed; monitor and analyze the funding of political parties; know who the party's financiers are; to know for what purposes the party money is spent; be able to compare and verify how much money has actually been spent on State subsidies and what actions have been declared by the parties to be made on this money.

For some civil society representatives, accessing the digital reporting system is also a need for a job in which they carry out their professional duties (for example, journalists, teachers, policy experts, etc.) 
It is interesting to note that some representatives of civil society have pointed out that, firstly, information on the funding of political parties is of interest to them, as citizens (electorate) and then as journalists.

The same trend is found in focus groups, for which the right to information and knowledge enables them to actively participate in the socio-political processes of the country.

„,... as a citizen, would allow me to participate in the exercise of the political control function. Respectively, being properly informed, I could punish or give trust to one or another political party. As future political scientist, I would use my research and analysis". (FG, male, 26 years, Chisinau).

„....as a voter, I can see how fairly the parties are reporting especially those who are in government, especially since they are our money, and as voter I want to see where this money is spent, I want to see how parties use public money, levies ... In what measure will correctly present the data, so you can judge and see what principles will be applied by them in the act of government". (FG, female, 38 years old, Chisinau).

An important aspect is the characteristics of the digital reporting system on the financing of political parties. Respondents' responses were not uniform, taking into account the needs they need and the utilities they expect from this system (Table 1).

Table 1. Which should be the most important features of a digital reporting system on the funding of political parties?

\begin{tabular}{|l|c|c|c|}
\hline Characteristics & CEC & Civil Society & Political parties \\
\hline Accessible & $100 \%$ & $63 \%$ & $83 \%$ \\
\hline Detailiat & $67 \%$ & $75 \%$ & $61 \%$ \\
\hline Comparable & $67 \%$ & $50 \%$ & $22 \%$ \\
\hline Timely & $67 \%$ & $37 \%$ & $44 \%$ \\
\hline Downloadable & $33 \%$ & $37 \%$ & $72 \%$ \\
\hline Easy to find & $0 \%$ & $37 \%$ & $28 \%$ \\
\hline
\end{tabular}

Source: Sociological research conducted by the authors

For both the CEC and the political parties, the most important feature is the accessibility of the reporting system $-100 \%$ and respectively $83 \%$. While civil society believes that the most important element should be detailing (75\% of respondents). Simultaneously 67\% of CEC representatives consider comparability, detail and opportunity as important elements of the digital reporting system, while political parties rather prefer to be downloadable ( $72 \%$ of respondents) and its detailed character $(61 \%)$. In contrast, civil society highlights accessibility (63\% of those interviewed) and comparability (50\%), considering them as important features of this system.

Note that for political parties comparability is not so appreciated (22\% of respondents), as well as by civil society and the CEC. For the latter two, comparability is nothing but a qualitative characteristic of the control and surveillance function that these entities exercise.

At the same time, it is important for civil society that the system should allow for the visualization of the donation evolution during several electoral campaigns that would ensure the transparency of political processes and facilitate access to information of public interest.

This system should also be easy to find by interested parties, most respondents pointing to the need to place on the official website of the CEC a section devoted especially to the digital reporting system. This box should contain the necessary information, which would meet all the expectations and queries of the parties surveyed, which we are going to analyze in the continuation of the study.

As far as the focus groups are concerned, for most of them accessibility is the most important feature of this system.

In line with the most important features of a digital reporting system, respondents have expressed their views on the functionalities that an electronic reporting system should have.

While CEC representatives unanimously consider sending online data as one of the most important functionality of the electronic reporting system, for those questioned by political parties $(83 \%)$, automatic saving of input data is the most important functionality of the system (Table 2). 
Table 2. What functionalities should an electronic reporting system provide?

\begin{tabular}{|l|c|c|c|}
\hline Features & CEC & $\begin{array}{c}\text { Civil } \\
\text { Society }\end{array}$ & $\begin{array}{c}\text { Political } \\
\text { parties }\end{array}$ \\
\hline Access to Interactive Technical Assistance (FAQ) & $33 \%$ & $25 \%$ & $44 \%$ \\
\hline $\begin{array}{l}\text { Ensure the possibility of further data completion } \\
\text { (option to re-enter the entered data) }\end{array}$ & $33 \%$ & $50 \%$ & $72 \%$ \\
\hline Providing delivery receipts for sent reports & $67 \%$ & $50 \%$ & $61 \%$ \\
\hline Notification of the reporting deadline & $33 \%$ & $63 \%$ & $50 \%$ \\
\hline Automatic saving of input data & $67 \%$ & $63 \%$ & $83 \%$ \\
\hline Multiple linguistic version & $5 \%$ & $63 \%$ & $33 \%$ \\
\hline $\begin{array}{l}\text { Generate reports printing based on predefined } \\
\text { templates }\end{array}$ & $67 \%$ & $63 \%$ & $72 \%$ \\
\hline Sending online data & $100 \%$ & $63 \%$ & $78 \%$ \\
\hline Downloadable & $33 \%$ & $75 \%$ & $44 \%$ \\
\hline Exploring and viewing archive data & $33 \%$ & $88 \%$ & $67 \%$ \\
\hline $\begin{array}{l}\text { Automatic synchronization of relevant data from } \\
\text { external sources }\end{array}$ & $33 \%$ & $40 \%$ & $11 \%$ \\
\hline
\end{tabular}

While for $88 \%$ of representatives of civil society, the most important functionality is the exploration and visualization of archive data. This option can be explained by the fact that most of the respondents are members of the journalistic community, experts and analysts in the field, for whom archive information is a source of comparability, opportunity and analysis.

In the second position, the CEC respondents $(67 \%)$ mentioned the automatic saving of the input data and the delivery of receipts for receiving the sent reports followed by generating the printing of the reports based on predefined templates.

For party representatives, sending online data $(78 \%)$, generate report printing based on predefined templates $(72 \%)$, and ensure the possibility of further data completion (72\%) have also been recognized as important functionalities of the system. Civil society, on the other hand, sees automatic synchronization of relevant data from external sources $(75 \%)$, followed by sending online data $(63 \%)$, generating report printing based on predefined templates, multiple linguistic version as important system functionalities.

With small differences, the results of focus group surveys were similar to those of civil society, highlighting the possibility of exploring and viewing archive data as well as automatically synchronizing relevant data from external sources.

An important element, often divergent and generating dissensions, especially in electoral campaigns, is donations to political parties. Given that the Regulation on the Financing of the Activity of Political Parties regulates expressly the way of evidence of donations (the Register of donations from legal entities, the Register of donations from individuals), we intend to find the respondents' opinion regarding what kind of information / data, tangential to party donations, should be made public (Table 3 ).

Table 3. What information about donation do you think should be made public?

\begin{tabular}{|l|c|c|c|}
\hline The nature of donations & CEC & Civil society & Political parties \\
\hline Name, surname of donor & $67 \%$ & $63 \%$ & $95 \%$ \\
\hline Donor status (physical / jur.) & $33 \%$ & $50 \%$ & $61 \%$ \\
\hline Donation amount (amount) & $100 \%$ & $100 \%$ & $89 \%$ \\
\hline $\begin{array}{l}\text { Date of transmission, receipt and } \\
\text { acceptance of the donation }\end{array}$ & $67 \%$ & $50 \%$ & $44 \%$ \\
\hline Donor work & $67 \%$ & $37 \%$ & $28 \%$ \\
\hline IDNP & $67 \%$ & $0 \%$ & $17 \%$ \\
\hline
\end{tabular}

Source: Sociological research conducted by the authors

Therefore, within the focus group CEC members proposed to set a ceiling on the donation amount.

„I think it must be determined from what ceiling of the donated sum, the donor becomes a public figure, ie his / her data becomes accessible to society. If the person donates large sums of money and influences PP's activity, then the legislator must set a certain amount of donated money. 
And then name, donor's name, donation amount, field of activity are made public. This would allow us to assume how accurate the information is". (FG, woman, 41 years old, Chisinau).

"And every donor will be aware that when he donates a large sum of money, information about him will become public. Information on the name, donor's name, donation amount, field of activity and date of donation must be made public". (FG, woman, 41 years old, Chisinau).

In this context, the analysis of the results shows that all interviewees rated the value of the donation with maximum score, which, in their opinion, should be made public (CEC and civil society $-100 \%$, political parties $-89 \%$ ).

After that it follows the donor's name and surname, and it is remarkable that $95 \%$ of respondents to political parties believe that this information would take precedence over the value of the donation.

For the CEC, as a supervisory and controlling body, it is important that the information on the date of receipt, receipt and acceptance of donations and donor work is also public (67\% of those surveyed). Also, 1/3 of the CEC respondents opted to publish the information whether or not the donor is a party member (contributor).

For political parties, as a person interested in limiting donor advertising, $61 \%$ of respondents believe that the donor's status (legal person / natural person) could also be made public, while most voiced disagreement about the inappropriateness of job publishing donor as well as IDNP.

The position of civil society representatives is, to a large extent, similar to that of the CEC. In addition to the donation value, it is considered necessary to make public the information regarding the date of receipt, receipt and acceptance of the donation (50\%). If civil party donors are not made public, civil society believes that their verification becomes a very difficult one, and the lack of rigorous control by the CEC creates an even greater sense of anxiety and mistrust in the political class.

Analysis of the focus group results denotes the same situation as for the CEC and civil society. Some of the respondents consider IDNP to be personal data, so they can not be public, others think that legal data donors should be made public on possible procurement data. For others, it is important to set a level of the donation ceiling, which, being exceeded, will condition the publication of donor data.

„Donor's name, donation value, workplace. I believe that in a normal democracy all the data should be published, but considering that in our country those who support some opposition parties are intimidated, the party members are persecuted, then I do not think that at the moment everything must be made public data". (FG, female, 38 years old, Chisinau).

„All but IDNP because it is confidential information”. (FG, female, 23 years old, Ialoveni).

From the practice of other countries, e-reporting systems for the funding of political parties are interconnected with other state electronic systems. Taking into account the objective pursued in this research, we intend to know the respondents' view of how the electronic reporting system on the financing of political parties, interconnected with other state electronic systems such as the Fiscal Service or the Public Services Agency ensures the reliability of data in financial reports. Respondents from all surveyed groups voiced confidence that, once interconnected with other state electronic systems, the electronic reporting system of political parties will ensure a higher quality of data accuracy in these reports.

Both civil society representatives (75\%) and CEC (67\%) consider that data veracity will be greatly assured, whereas respondents in the political parties have reserved the prospect of a high degree of assurance of veracity, as they are only half of those surveyed.39\% of party representatives believe that the interconnection of systems would provide a medium-sized data veracity, with some CEC employees (33\%) being the same. The skepticism of such an opportunity for civil society, but also for the CEC, is followed by the negative responses of representatives of the political class, who believe that the interconnection will poorly assure the veracity of the data $(6 \%)$ and for $5 \%$ this innovation will not change not true of the reports presented in the CEC address.

Only representatives of civil society responded that at the moment they do not know whether the interconnection with other state systems will ensure the veracity of the data presented in the reports, representing $12 \%$ of those questioned.

This question correlates with the responses to public information on the donation character. Representatives of the journalist community came up with the suggestion that the electronic system interconnected with other systems should ensure that the donor's name, donor's name and donation match the data in the Donor's Income Statement.

For the survey focus groups, it was difficult to answer the question of interconnecting the electronic platform to other public systems, due to the lack of knowledge of this opportunity. 
Analyzing the responses to the respondents' expectations of the e-reporting platform to be introduced, all respondents said that it (the platform) will ensure a change for the better, being aware that this process will be gradual. At the same time, the platform must be functional, accessible, make it easier to report and reduce reporting time. Representatives of civil society and political parties are hoping that the digital platform will bring transparency into funding.

At the same time, the CEC representatives stressed the possibility of facilitating data processing, verifying and establishing their veracity; will accountability to political parties, increase public confidence in political parties and strengthen democracy. It also opts for a cooperation with commercial banks, whose systems are linked to those of the CEC to ensure the exchange of data on bankroll balances of political parties.

In turn, party representatives have the following expectations: platform to allow connection and synchronization between 1C Accounting Program and the CEC Reports annexes (eg Contribution Register and Donor Register to be integrated into "1C Accounting"; be easy to manage the Electronic Register of donations. For example, once the donor's tax code is entered, the platform automatically exposes all donor data, which would make it easier for the donor to save time; consultation by telephone or on-line is also provided in Russian. Some respondents mentioned that few of the CEC employees know Russian. This expectation reflects the specifics of the ethnic diversity of the Republic of Moldova.

It is important for civil society that with the launch of the electronic platform, citizens will be more actively involved in political activity. However, there are also less optimistic opinions that the platform will regulate to a certain extent the given situation, but the state of "captured state" will again lead to the feeling that "everything is good for us" (quoted from the answer of a representative of the civil society).

The comparative analysis of the replies regarding the frequency of financial reporting to CEC shows that: $1 / 3$ of CEC representatives, half from political parties and $38 \%$ of civil society respondents believe that reports can be presented annually. $67 \%$ of those surveyed within the CEC opted to report twice a year. Just $40 \%$ of respondents to political parties, as well $25 \%$ of civil society believes that financial reports can be submitted twice a year. Although $25 \%$ of civil society, in their capacity as political watchdog, believes that reporting to the CEC must be done 4 times a year, and $12 \%$ - and more frequently.

Most of those in the focus groups have opted to submit their financial reports twice a year. At the same time, some of them consider that party expenses need to be published monthly, especially in pre-election and electoral campaigns.

The legal framework in the Republic of Moldova provides for a mixed model of political financing (collection of private donations and government funding). The state budget funds are monthly transferred to the accounts of political parties, which gained votes in national and local general elections in the conditions and proportions stipulated by the current legislation through the Central Election Commission [4: 24-25].

The issue of subsidies is the theme of heated litigation in society, which is why the respondents 'opinion about the transparent reflection of subsidies in the parties' financial reports is of interest to the survey. Representatives of the CEC $(67 \%)$ and of the political parties (83\%) considers that state subsidies are transparently reflected, but only $25 \%$ of the civil society respondents consider the same. From the other side, 33\% of CEC respondents and 63\% of civil society believes that state subsidies are not transparently reflected. In the opinion of those interviewed at the CEC, the cause would be the inconvenient process of checking the financial reports, which at the moment is presented twice a year. In the case of automated reporting, then the verification would be more effective and more qualitative, and the reporting could be done 1 per year, the CEC concluded.

Respectively, in the opinion of civil society, the causes are the absence of sanctions, or at least their superficiality for the non-transparency of data. Also mentioned was the unwillingness to present the real situation within the party, because the source of the financial means can often not be justified, which is illegal. In the case of CEC checks on the use of state subsidies, double standards apply to opposition parties and coalition / ruling parties. Some civil society respondents have exemplified that opposition parties have a much higher risk of applying the most severe sanctions than for coalition for the same offense.

A more special situation is found in $17 \%$ of respondents to political parties who consider that state subsidies are not reflected or at least not properly reflected in the financial reports. Among the causes, there are many articles (which are essentially general) in the financial reports of political parties, without explanations as to what kind of expenses / revenues are attributed to them. Respectively, they proposed a more detailed breakdown of expenditure, typology (eg staff costs, etc.).

For most focus groups, it was difficult to give an appreciation to the transparency of public subsidies, on the grounds that such information is not known to them. 
In the opinion of the members of the CEC, the reflection of the public subsidies is done according to the requirements of the normative framework. However, the hypothesis is confirmed that a more detailed typology of party spending is needed.

„Another is the question: what is this money to spend, because if half a million are spent on staff, the question arises how much the political party personally has, or what would be the amounts paid for remuneration. Here is the field of analysis, research, control, but also the lack of legal regulations...... In the area of subsidies can be established clearer criteria or ceilings on the use of public money" (FG, female, 41 years old, Chişinău).

Following the questioning of the target groups about the truthfulness and fairness of the financial reports, it is noted that the national legal framework influences the financial transparency of the political parties. By asking for the opinion of respondents in the interviewed groups on the impact of the legal framework, the representatives of the CEC unanimously believe that the legal framework ensures transparency, but control measures are needed.

Thus, in FG with CEC members a number of proposals were made regarding the necessity to modify the existing normative framework:

„, The Personal Data Protection Act does not contain full clarity. It is not clear under what conditions and in what circumstances some data may be made public and others not. This clarity will be beneficial not only to the CEC as a public authority, but also to citizens, who also treat differently the provisions in the law. There are situations where the provisions of the Access to Information Act and the Personal Data Protection Act contradict each other. When clear regulation is in place, the whole society will benefit" (FG, male, 39 years old, Chișinău).

With regard to ensuring financial transparency by the legal framework, only $45 \%$ of respondents to political parties believe that the legal framework ensures transparency, and $35 \%$ believe that control measures are also needed. On the other hand, only $12 \%$ claim that the legal framework does not reflect the transparency and the new ways of receiving the money, respectively $6 \%$ do not know the state of financial transparency of the political parties in the Republic of Moldova, which shows a high degree of ignorance of the way of financing political organizations - a criterion demanded by a functioning democracy (Table 4).

Table 4. Do you think that the existing legal framework ensures the financial transparency of political parties?

\begin{tabular}{|l|c|c|}
\hline & Civil society & Political parties \\
\hline Ensures, but control measures are required & $50 \%$ & $35 \%$ \\
\hline $\begin{array}{l}\text { No, the legal framework does not reflect } \\
\text { the new ways of receiving money }\end{array}$ & $50 \%$ & $12 \%$ \\
\hline Yes, to a great extent & $0 \%$ & $45 \%$ \\
\hline Don't know & $0 \%$ & $6 \%$ \\
\hline
\end{tabular}

Source: Sociological research conducted by the authors

In the case of civil society, opinions were divided into half. Thus, $50 \%$ of respondents said that the legal framework ensure transparency, but control measures are needed, and the other side shows that the legal framework does not ensure transparency, not reflecting new ways of receiving money.

The main beneficiaries of the electronic financial reporting system are political parties. This fact led to the formulation of a set of questions addressed directly to the parties. The goal was to determine the level of use of technological resources by political organizations, as well as to know their opinion on the launch of the electronic reporting system. A specific situation is evidenced by contributions, donations to organizations. Even if some political parties have the "1C Accounting" program, membership fees in the territory are fixed on paper and are centrally introduced by the party's treasurer. At the same time, following the interviews, it was found that some parties have a personal information storage system, such as the databases developed in Excel (such as the Members' Register, the Donor Register), which is connected through elaborated programs customized with 1C accounting software, which allows automatic data logging.

Political parties (95\%) said that the presentation of financial reports to the CEC is a responsible person. But only $78 \%$ of them have the necessary training in the field (financial, accounting), while $22 \%$ of the responsible people do not have the necessary training in the financial field. We can assume that the difficulties encountered in the process of reporting on the financial activity of political parties can be explained not only by the lack of experience of reporting (2016) but also by the lack of a necessary qualification in the field. This data correlates with the answers to the 
question whether you have difficulties in the process of developing the financial report on electronic support, $83 \%$ responded affirmatively and only $17 \%$ do not encounter difficulties.

In the interviews it was found that $60 \%$ of the employees of the political organizations use the electronic or mobile signature for the performance of their job duties and $40 \%$ do not possess. This creates situations in which political parties also use other electronic public financial reporting services. More than half of the political parties use electronic public financial reporting services at the State Tax Service (STS), client-bank and CEC solutions. Less than half of the parties use financial reporting in relations with the National Bureau of Statistics (NBS), the National House of Social Insurance (NHSI). These data demonstrate that political organizations have potential and experience of electronic financial reporting. But at the same time political parties mentioned that they need support from the CEC for the implementation of an electronic reporting system. The most requested options were on-line training and support (84\%). At the same time, $44 \%$ of respondents indicated the need to develop an explicit, exemplary electronic guide, which can be downloaded from the official CEC website, and 39\% opted for telephone support.

Conclusions. The study provides the following conclusions:

All respondents support the idea of implementing an electronic reporting system on political parties' income and expenditures, depending on the specifics of the target group, and argue for the need to launch such a system.

The results of the study confirm that political parties have sufficient technological and human resources. It was also found that more than half of the employees of the political organizations use the electronic or mobile signature to perform their job duties. This conditionates situations in which political parties also use other electronic public financial reporting services. Research data reflects the fact that political parties have potential and experience of electronic financial reporting, and the implementation of an electronic revenue and expenditures reporting system is not an impediment to them.

At the same time, political parties mention the need for informational support from the Central Electoral Commission, arguing that the applied training methods on the financial reporting practice of political parties has been a positive experience. The study reveals the presence of a process of forming the financial culture of political parties. At the same time, there is a culture of supervision of the financial management of the activity of the political parties, which is carried out by the Central Electoral Commission as a pillar of the activity in the field of monitoring the activity of the political parties. Further development of the party's financial reporting culture will generate a viable and qualitative transparency of this process, as well as financial accountability and discipline of political parties, and last but not least, to increase the confidence of the whole society in national political organizations. Civil society hopes that the launch of the electronic platform will involve citizens in political life as well as diminish the level of political corruption. However, the views expressed by civil society representatives on the launch of the digital reporting system are less optimistic than the rest of the surveyed groups.

\section{REFERENCES}

1. Decision of the Central Electoral Commission no. 4401 for the approval of the Regulation on the Financing of the Activity of Political Parties. In: Official Gazette of the Republic of Moldova no. 32-37 of 12.02.2016.

2. Law no. 294 on political parties. In: Official Gazette of the Republic of Moldova no. 42-44 of 29.02.2008.

3. Money in Politics Handbook: A Guide to Increasing Transparency in Emerging Democracies. Office of Democracy and Governance Bureau for Democracy, Conflict, and Humanitarian Assistance Agency for International Development. Washington, 2005, http://siteresources.worldbank.org/ INTWBIGOVANTCOR / Resources / usaid moneypolitics.pdf

4. Report "Financing political parties in the Republic of Moldova. Retrospective of 2016", https://promolex.md/wp-content/uploads/2017/05/raport_RO_web.pdf 